\title{
Synthesis of multicore phenol formaldehyde microcapsules and their application in polyurethane paint formulation for self-healing anticorrosive coating
}

\author{
Rajendra S Jadhav', Vishal Mane', Avinash V Bagle², Dilip G Hundiwale², Pramod P Mahulikar² \\ and Gulzar Waghoo ${ }^{1 *}$
}

\begin{abstract}
Background: This paper describes the microencapsulation of linseed oil along with drier and corrosion inhibitor in polyurethane coating.

Results: Linseed oil along with drier and corrosion inhibitor was encapsulated in phenol formaldehyde microcapsules successfully by in situ polymerization process. These microcapsules were characterized by Fourier transform-infrared and nuclear magnetic resonance spectroscopies, and their surface morphology was studied by scanning electron microscopy. The particle size of the prepared microcapsules was estimated by optical microscopy and confirmed using a particle size analyzer. The self-healing properties as well as anticorrosive performance of encapsulated microcapsules were studied in polyurethane coating. Corrosion protection of coatings with microcapsules containing linseed oil, corrosion inhibitor, and drier was compared with pristine coating free from microcapsules.
\end{abstract}

Conclusions: The cracks in the paint film could be successfully repaired by the release of linseed oil from microcapsules ruptured under stimulated mechanical action, while corrosion inhibitor plays an important role to prevent the corrosion in a scribed line region.

Keywords: Self-healing, Phenol formaldehyde, Microcapsules, Linseed oil, Anticorrosive performance, Polyurethane coating, Corrosion inhibitor

\section{Background}

Self-healing materials encapsulated in polymeric backbone represent a new research area for functional materials in paints and coatings. Microencapsulation techniques can be utilized to encapsulate a range of substances of different phases such as gasses, liquid, and solids. Depending upon the substance with required characteristics to be encapsulated, one can develop a technology which can have multiple applications [1,2]. Several functional materials have been encapsulated [3-5] for various applications like sustained drug

\footnotetext{
* Correspondence: g.waghoo@shalimarpaints.com

${ }^{1}$ Research and Development Center, Shalimar Paints, Ltd., Nasik Maharashtra 422403, India

Full list of author information is available at the end of the article
}

release [6], electrorheological fluids [7], intumescent fire-retarding powders [8-10], preservation of flavors, electrophoretic displays, textiles, and biotechnology [11-15]. Self-healing polymeric materials have built-in ability to fill the microcracks developed during mechanical action [16,17], which can occur autonomously or be activated after an application of a specific stimulus (e.g., heat, radiation).

Paints are extensively used on various substrates for aesthetics as well as for protection in their service life period. In the case of paints used for protection in a corrosive atmosphere, the coating film undergoes changes in surface morphology, leading to the formation of microcracks which subsequently propagate and expose substrate to atmospheric moisture and oxygen [17]. In our previous 
work, we have demonstrated how these microcracks, if healed, can help in regaining the anticorrosive performance. This was achieved by the healing efficiency of epoxy coating using phenolformaldehyde (PF) microcapsules containing linseed oil and drier [16].

In this work, we report the microencapsulation of linseed oil along with drier and corrosion inhibitor in polyurethane coating. Linseed oil due to its high content of unsaturated esters of oleic acid, linoleic acid, and linolenic acid is susceptible to polymerization reactions upon exposure to oxygen in air. This polymerization results in the rigidification of the material, protecting the metal from corrosive species. The schematic representation of the mechanism of drying oil is shown in Scheme 1. Microcapsules having PF as shell and linseed oil, drier, and corrosion inhibitor as core were synthesized by in situ polymerization. The schematic representation of this in situ polymerization is shown in Scheme 2. The efficiency of these microcapsules in healing cracks in polyurethane coating and corrosion protection has been studied and further demonstrated.

\section{Methods}

\section{Characterization}

Infrared (IR) spectra of the samples were recorded on $\mathrm{KBr}$ pellets using a Fourier transform-infrared (FTIR) spectrometer (Perkin Elmer Spectrum One, 8400, PerkinElmer, Waltham, MA, USA). Nuclear magnetic resonance (NMR) spectra of the samples were recorded on Bruker $300 \mathrm{MHz}$ (Bruker AXS, Inc., Madison, WI, USA) in $\mathrm{CDCl}_{3}$. The PF microcapsules were visualized using an optical microscope, whereas the surface

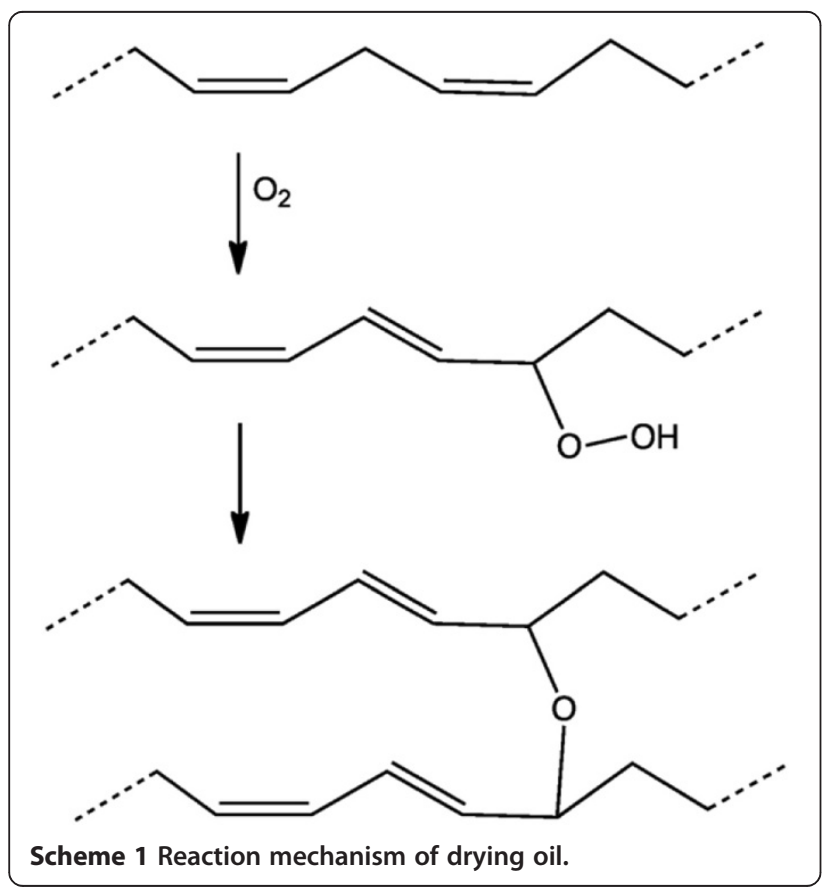

morphology and capsule shell thickness were examined using a scanning electron microscope (SEM; JEOL JSM 6360, JEOL Ltd., Akishima-shi, Japan). Microcapsules were mounted on a conductive stage and ruptured with a razor blade to facilitate membrane thickness measurement. The particle size was analyzed using a laser particle size analyzer (Microtrac X 100, Microtrac, Largo, FL, USA). The coating thickness was measured using a digital meter (Positector, DeFelsko, Ogdensburg, NY, USA). Immersion studies of the coatings were carried out in $5 \% \mathrm{NaCl}$ solution. The sample panels were tested for a total exposure time of $480 \mathrm{~h}$. The corrosion of the damaged area was monitored by visual inspection using a digital camera (Olympus FE-25, 10 megapixels, Olympus Corporation, Shinjuku, Tokyo, Japan).

\section{Quantity of core material present in microcapsules}

The percentage of core material present in PF microcapsules was determined by the extraction of core material using the Soxhlet apparatus. A known weight of microcapsules $\left(W_{\mathrm{m}}\right)$ was transferred to a thimble, and extraction was carried out using xylene as a solvent. After $2 \mathrm{~h}$ of extraction, thimble was carefully taken out from the Soxhlet apparatus and dried in an oven at $80^{\circ} \mathrm{C}$ to $85^{\circ} \mathrm{C}$ for $12 \mathrm{~h}$. The final weight of the shells $\left(W_{\mathrm{s}}\right)$ was noted. The quantity of linseed oil was determined with the help of following equation [16]:

$$
\text { Percentage of core material }(\%)=\frac{W_{m}-W_{s}}{W_{m}} \times 100
$$

\section{Controlled release study}

Controlled release behavior of phenol formaldehyde microcapsules containing dual core and multicore was investigated using the loss after drying method. In this method, $0.1 \mathrm{~g}$ of microcapsules was transferred into dry Gooch crucible with stop cork followed by the addition of $10 \mathrm{~mL}$ of xylene with gentle stirring at room temperature. The microcapsules were kept in contact with xylene for extraction over a period of $60 \mathrm{~min}$, and then, the eluent containing the core material was collected by opening the stop cork. This process was repeated at 2-h interval, and all the core materials were extracted.

\section{Self-healing and anticorrosion studies}

The PF microcapsules were used for the preparation of PU self-healing coatings. The PU coatings were prepared by dispersing 2 wt.\% of PF microcapsules in PU clear as well as white paint formulations. The PU clear coatings were applied by dip coating method on a glass slide with the size of $20 \mathrm{~mm} \times 50 \mathrm{~mm} \times 2 \mathrm{~mm}$ having a dry film thickness (DFT) of about $50 \mu \mathrm{m}$, while the coatings of 


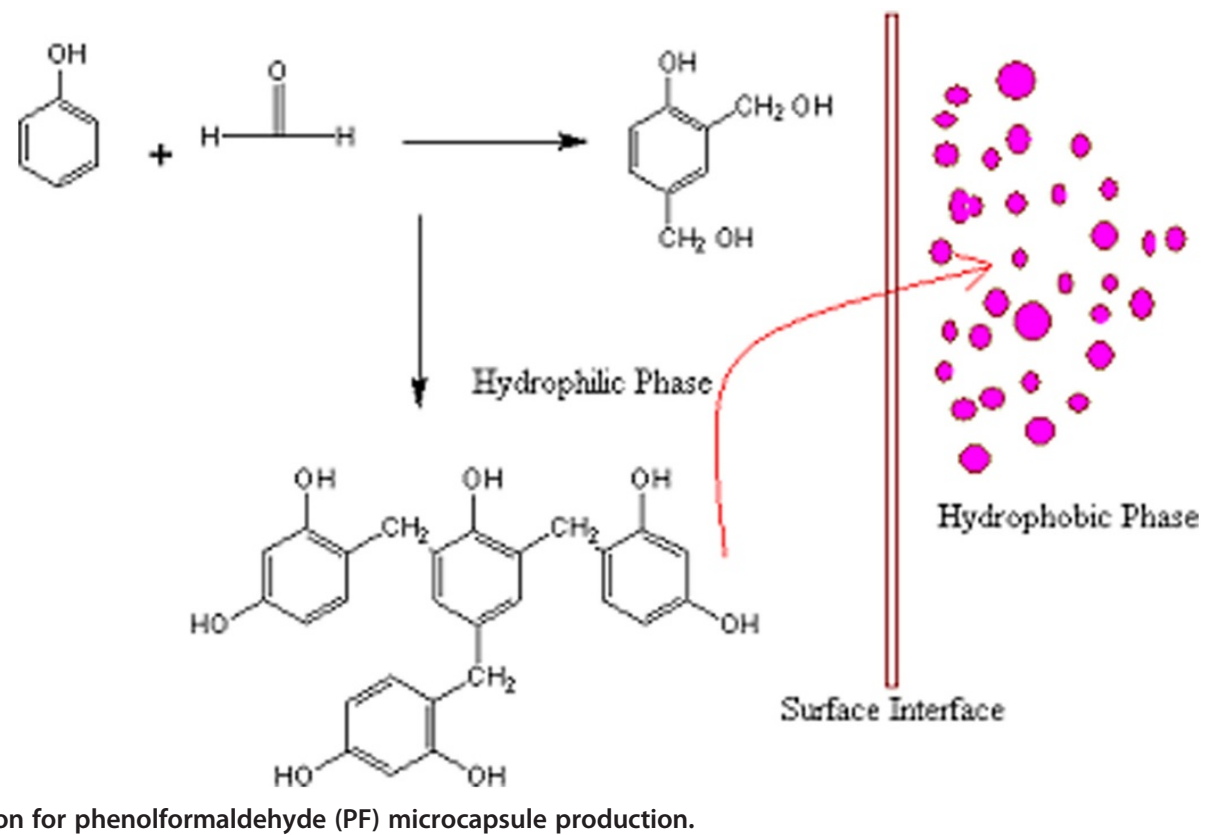

the white paint were applied using a conventional spray gun on steel strips with the dimension of $150 \mathrm{~mm} \times 100 \mathrm{~mm} \times$ $1 \mathrm{~mm}$ having a DFT of about $100 \mu \mathrm{m}$. The self-healing of PU clear coating containing microcapsules was demonstrated using an optical microscope. The self-healing and anticorrosion function of PU paint film were evaluated through immersion studies of coated steel samples by comparing with steel samples without microcapsule as a control. Damage was induced by scribing a crosscut through a razor blade having a cut thickness of about $10 \mu \mathrm{m}$, and after scribing, the samples were allowed to heal at room temperature for $24 \mathrm{~h}$.

\section{Results and discussion \\ FTIR and NMR analysis}

The core material extracted as explained in the 'Quantity of core material present in microcapsules' section was used for FTIR and NMR analysis. In the case of FTIR spectroscopic analysis for PF shell (Figure 1a), the absorption bands observed at 1,696 and $1,462 \mathrm{~cm}^{-1}$ were attributed to the $\mathrm{C}=\mathrm{C}$ aromatic ring vibrations, and the bands at 1,274 and $1,154 \mathrm{~cm}^{-1}$ were characterized to the $\mathrm{C}-\mathrm{C}-\mathrm{O}$ asymmetric stretching and $\mathrm{C}-\mathrm{H}$ in plane deformations, respectively. The bands at 980 and $719 \mathrm{~cm}^{-1}$ belonged to the $\mathrm{C}-\mathrm{H}$ out of plane vibrations. The band at $1,384 \mathrm{~cm}^{-1}$ corresponding to the phenolic $\mathrm{O}-\mathrm{H}$ in plane bending was also detected for PF resin $[18,19]$. However, for linseed oil (Figure 1b), the main stretching absorption bands were observed for ester $\mathrm{C}=\mathrm{O}\left(1,745 \mathrm{~cm}^{-1}\right)$, aliphatic $\mathrm{C}=\mathrm{C}\left(1,696\right.$ and $\left.1,548 \mathrm{~cm}^{-1}\right)$, and ester $\mathrm{C}-\mathrm{O}\left(1,384\right.$ and $\left.1,278 \mathrm{~cm}^{-1}\right)$ groups. For core $\mathrm{A}$ (linseed oil/drier/Alcophor AC) (Figure 1c), the same absorption bands were observed as compared to linseed oil. Finally, for the confirmation of corrosion inhibitor in core A sample, additional information was collected from ${ }^{1} \mathrm{H}$ NMR spectral analysis of core A (Figure 1d) and linseed oil (Figure 1e) samples separately. In the NMR spectra, some extra multiplets were observed for core A sample in the range of $\delta 0.56$ to $2.45 \mathrm{ppm}$ due to the presence of aliphatic protons $(\delta 0.86 \mathrm{ppm})$ and also for $-\mathrm{OCH}_{3}$ $(\delta 2.10 \mathrm{ppm})$ present in Alcophor AC [20,21]. The multiplets at $\delta 4.95$ to $5.56 \mathrm{ppm}$ and $\delta 7.12$ to $7.45 \mathrm{ppm}$ were observed for aliphatic -OH groups and aromatic -OH groups, respectively, present in tannin (polyphenolic compound). The NMR study has confirmed thatcore A contained analkoxy-modified tannin compound, i.e., Alcophor AC.

\section{Effect of the rate of agitation during the synthesis of microcapsules}

The PF microcapsules were synthesized at different agitation rates and observed using an optical microscope. The obtained results are depicted in Figure 2, which clearly show that spherical microcapsules were obtained at all agitation rates. At low agitation rate (200 rpm), the microcapsules obtained were comparatively large having the diameter of 100 to $120 \mu \mathrm{m}$ (Figure 2a). At 300 to $400 \mathrm{rpm}$, the microcapsules with reduced size with average diameter in the range of 40 to $50 \mu \mathrm{m}$ were obtained (Figure 2b,c). The sizes of microcapsules synthesized at $500 \mathrm{rpm}$ were found to be in the range of 20 to $40 \mu \mathrm{m}$ (Figure 2d). These might be due to increased interfacial area and more homogeneous reaction occurring at the microcapsule surface with increase in agitation rates. It 


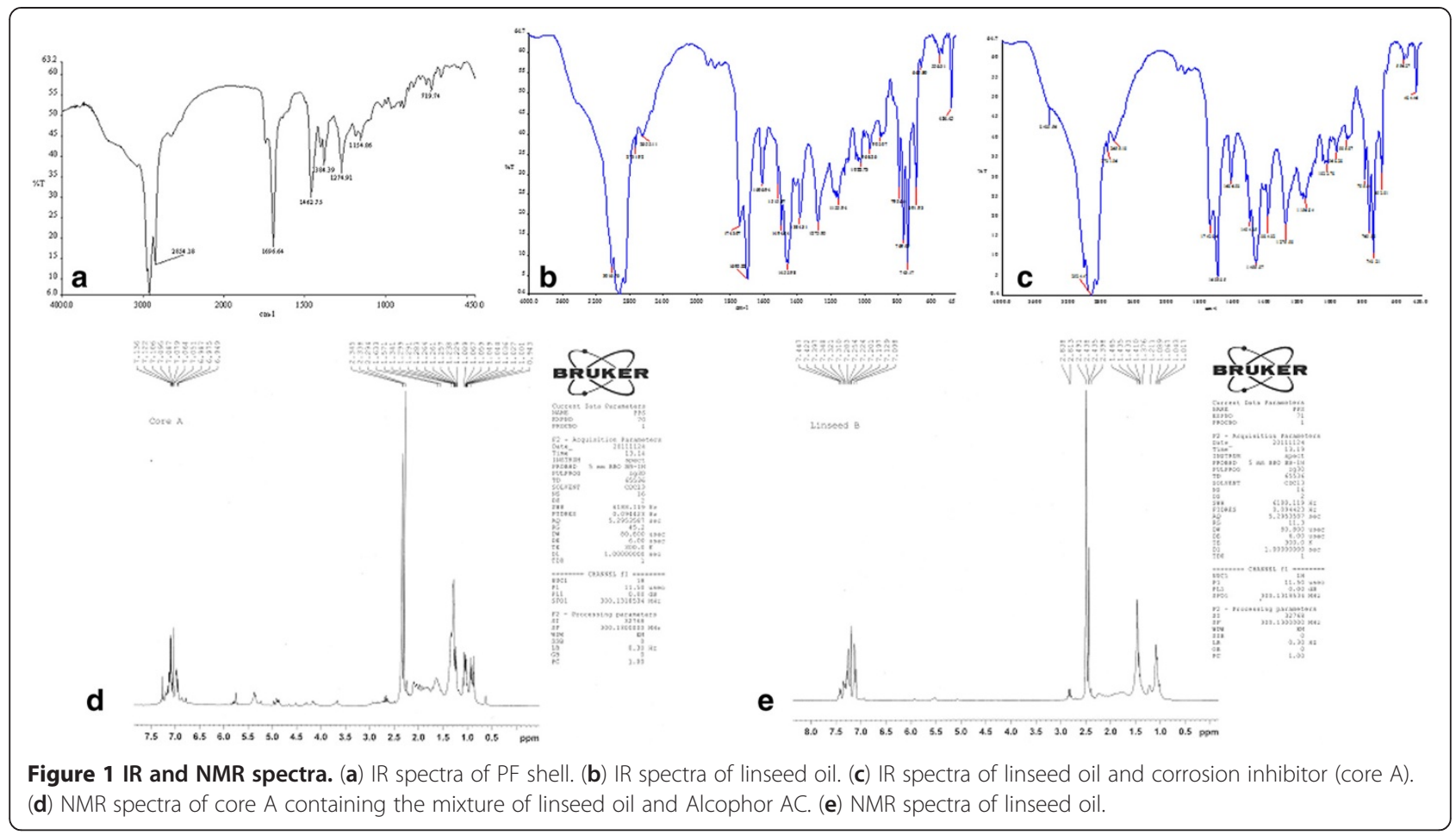

means that a high agitation rate $(\geq 500 \mathrm{rpm})$ producesa dispersion force which might be sufficient to breakdown the large oil droplets into smaller ones and can uniformly disperse the tiny oil droplets into the emulsion [22].

\section{SEM analysis}

The SEM micrographs further supported that PF microcapsules are spherical and round in shape with awrinkle-free surface morphology. The particle size of microcapsules synthesized at $500 \mathrm{rpm}$ was found to be 20 to $40 \mu \mathrm{m}$ (Figure 3a). Surface morphology of a single PF microcapsule clearly showed the smooth and even surface of microcapsules (Figure 3b). The microcapsules were ruptured to measure the shell thickness, and it was found to be 0.4 to $0.5 \mu \mathrm{m}$ (Figure 3c). During the formation of PF microcapsules, resorcinol plays an important role to combine and crosslink phenol formaldehyde oligomers, leading to the formation of a
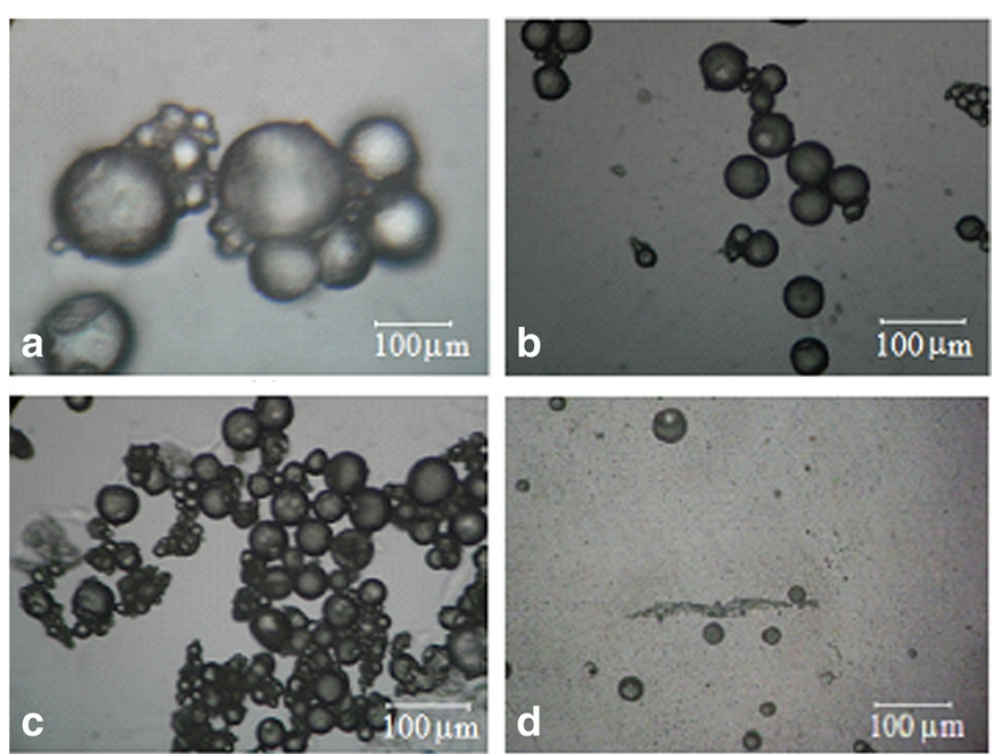

Figure 2 PF/linseed/Alcophor AC microcapsules obtained at various agitation rates. (a) 200, (b) 300, (c) 400, and (d) 500 rpm. 

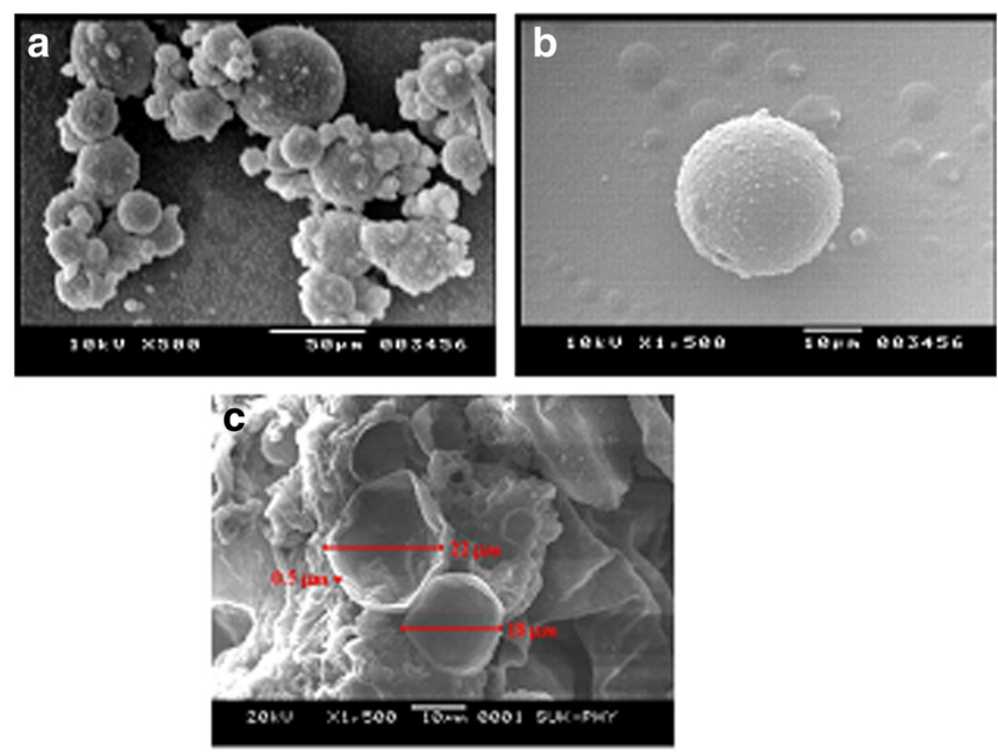

Figure 3 SEM micrographs. (a) PF/linseed/Alcophor AC microcapsules at $500 \mathrm{rpm}$, (b) surface morphology of microcapsule, and (c) ruptured shells with thickness.

tough protective uniform shell for the active core material.

\section{Particle size analysis and determination of the volume of} the core

The observed results of the particle size distribution of the PF microcapsules are shown in (Figure 4a). In the particle size histogram of PF microcapsules, the overall size ranged between 5 and $100 \mu \mathrm{m}$, and the mean particle size obtained was $\pm 30 \mu \mathrm{m}$. The circumference and volume of each individual microcapsule and core material present in it can be easily calculated, as depicted in Figure $4 \mathrm{~b}$, by $2 \pi r$ and $4 / 3 \pi r^{3}$ equations, where $r$ is the radius of microcapsule, $h$ is the shell thickness, and $r$ is the radius of core which is equal to $r-h$. In a mean particle size of $30 \mu \mathrm{m}$ having a shell thickness equal to $0.5 \mu \mathrm{m}$, the circumference of microcapsules calculated was $94.2 \mu \mathrm{m}$ and the circumference of core material was $91.06 \mu \mathrm{m}$. The volume of active core material present in the mean particle size of the microcapsule has been estimated as $12,731.66 \mu^{3}$.

\section{a}

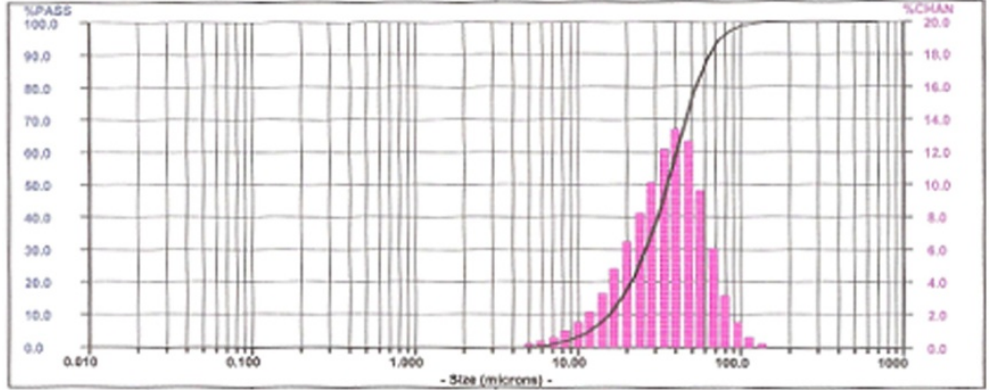

b

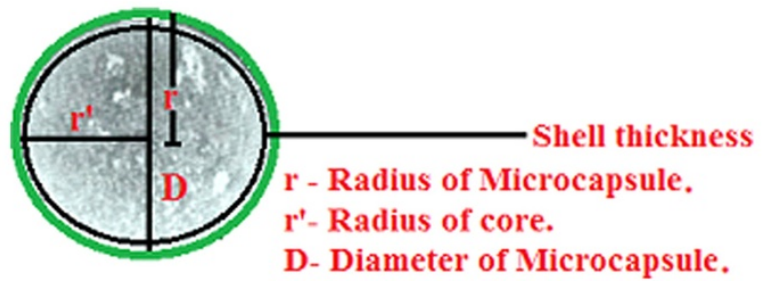

Figure 4 (a) Particle size histogram of PF/linseed/Alcophor AC microcapsules, (b) calculation of volume of active core material. 
Table 1 Quantitative analysis of core material released from PF/linseed and PF/multicore microcapsules

\begin{tabular}{ccc}
\hline Time (h) & $\begin{array}{c}\text { Core released of PF/ } \\
\text { linseed oil/Alcophor AC } \\
\text { microcapsules (\%) }\end{array}$ & $\begin{array}{c}\text { Core released of PF/ } \\
\text { linseed oil } \\
\text { microcapsules (\%) }\end{array}$ \\
\hline 0 & 0 & 0 \\
2 & 11.88 & 11.3 \\
4 & 56.43 & 55.9 \\
6 & 77.22 & 76.78 \\
8 & 85.14 & 85.11 \\
\hline
\end{tabular}

\section{Quantity of core material present in microcapsules and} controlled release study

The amount of dual and multicore encapsulated in PF microcapsules was determined using the Soxhlet apparatus and calculated as described in the 'Quantity of core material present in microcapsules' section. About $85 \%$ of core material was found to be present in both microcapsules. The results were confirmed in controlled release study as per the procedure described in the 'Controlled release study' section. The percentage of core material released slowly from both microcapsules is summarized in Table 1. About $85 \%$ core material was collected in $8 \mathrm{~h}$ from both microcapsules. This controlled release of core material would be useful in the efficient healing ability of the damaged coating and for better corrosion protection.

\section{Self-healing and anticorrosion studies}

In our previous work, it has been established that linseed oil and drier present in PF microcapsules play a vital role, providing a successful method to heal the cracks and inhibit the corrosion process in epoxy coating [16]. The role of linseed oil, drier,and corrosion inhibitor present in PF microcapsules for healing of PU coatings is reported here. The evaluation of self-healing and anticorrosive properties of the synthesized PF microcapsules were carried out as described in the 'Self-healing and anticorrosion studies' section.
The damage to the coating was induced by scribing a crosscut through a razor blade having a cut thickness of about $10 \mu \mathrm{m}$, and after scribing, the samples were allowed to heal at room temperature for $24 \mathrm{~h}$. First, the PU clear coatings with and without multicore PF microcapsules were observed under an optical microscope to determine the healing action of microcapsules. The images in Figure 5a,b clearly depict the self-healing ability of coating containing PF microcapsules. In the case of coating without PF microcapsule, the scribed portion appears to be hollow devoid of any material, whereas the scribed part of the coating containing PF multicore microcapsules appears as black deposition comprising of filled core material released from ruptured microcapsules. The images also depict the presence of smooth and spherical PF microcapsules dispersed in the coating portion which was not scribed.

The self-healing ability was further confirmed by evaluating PU paint-coated panel with and without microcapsules by immersion studies. It was observed that the PU paint-coated panel without microcapsules quickly corroded within $120 \mathrm{~h}$ of immersion in 5\% salt solution (Figure 6a). However, the PU-coated panels with dual core as well as multicore microcapsules were found to be free from corrosion, rust, and blisters at the scribed lines of crosscut after $120 \mathrm{~h}$ of immersion studies (Figure 6b,c). In addition, it was interesting to note the healing of cracks in the crosscut part of coating containing microcapsules. The extent of healing was found to be higher for multicore as compared to dual core.

In the further study, after $120 \mathrm{~h}$ of immersion, on these same three panels, the numbers of horizontal cuts were made, and self-healing efficiency was evaluated for another $480 \mathrm{~h}$ of immersion studies. The panel without microcapsules showed extensive rust formation, blisters most readily within the groove of the scribed area, and also extending rusting, blistering across the substrate surface (Figure 7a). The panels with dual-core microcapsules exhibited better corrosion resistance (Figure $7 \mathrm{~b}$ ). The anticorrosive performance is due to the healing
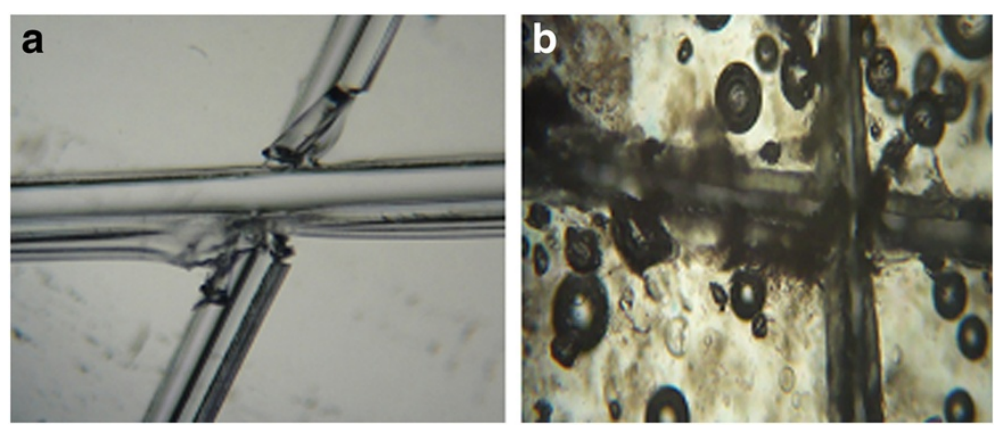

Figure 5 Self-healing ability of the coating - (a) clear coating and (b) coating with microcapsules. 

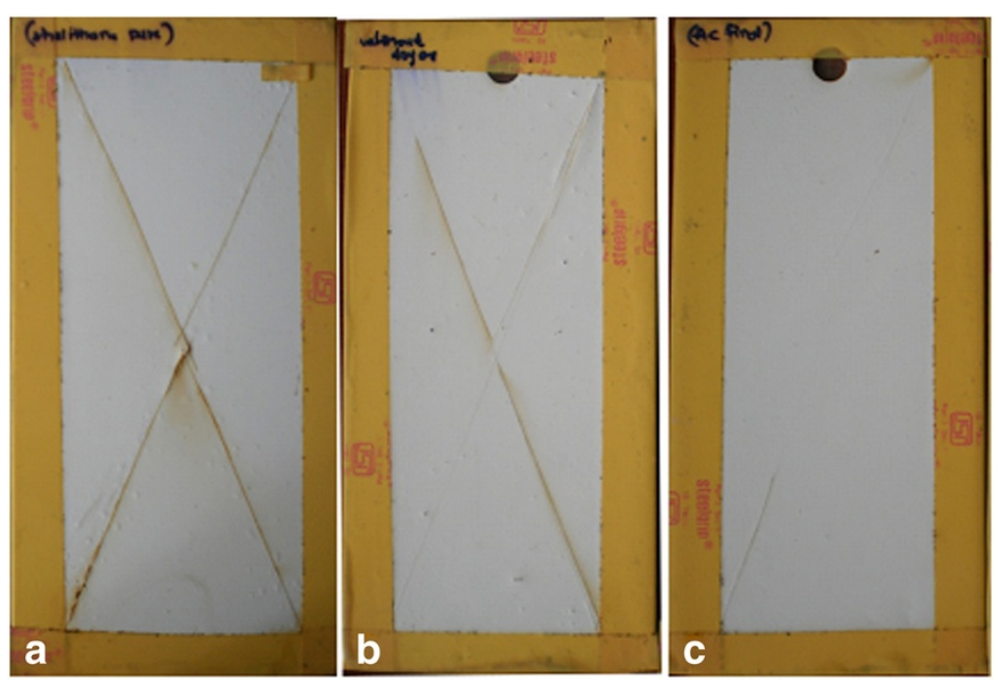

Figure 6 Crosscut panels after 120-h immersion studies. (a) Pristine PU coating, (b) coating with PF/linseed/drier microcapsules, and (c) coating with PF/linseed/drier/corrosion inhibitor microcapsules.

induced by linseed oil released from ruptured microcapsules, filling the cracks and forming a film by oxidative polymerization with atmospheric oxygen. The panels with PF multicore microcapsules showed even better corrosion protection as compared to the other two coatings with most of the cracks in the coating being healed as well as prevented from the corrosion formation in the scribed line region (Figure 7c). The presence of corrosion inhibitor in the multicore microcapsules has played an additional role in the protection against corrosion.

\section{Experimental \\ Materials}

The materials used in the experiments include linseed oil (Calf Brand, Pune, India), phenol, 37\% formaldehyde solution, resorcinol, xylene, ammonium hydroxide, ammonium chloride, hydrochloric acid and polyvinyl alcohol (SD Fine Chemicals Ltd., Mumbai, India), Shalithane XL HB Finish White - a two-pack polyurethane (PU) paint containing base and accelerator and Shalithane XL HB Finish Clear - a two-pack PU clear coating containing base

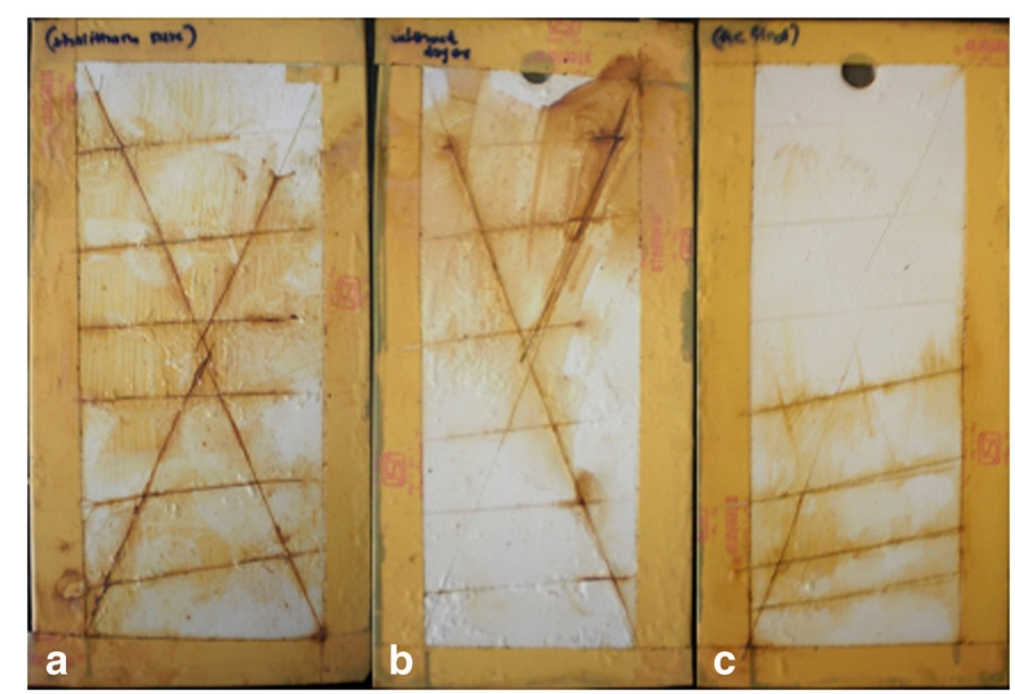

Figure 7 Crosscut panels after 480-himmersion studies. (a) Pristine polyurethane coating, (b) coating with PF/linseed microcapsules, and (c) coatings with PF/linseed/Alcophor AC microcapsules. 
and accelerator (Shalimar Paints Ltd., Mumbai, India), and Alcophor AC - an alkoxy-modified tannin compound used as corrosion inhibitor (Cognis, Monheim, Germany). All these chemicals were used as such without any further purification in the experiments.

\section{Synthesis of PF microcapsules}

Microcapsules were prepared by in situ polymerization by oil-in-water emulsion technique. Typically, $5 \mathrm{~mL}$ of 5 wt.\% aqueous solution of polyvinyl alcohol was mixed with $150 \mathrm{~mL}$ of distilled water in a three-necked flask. Under agitation, $3.76 \mathrm{~g}$ of phenol and $0.5 \mathrm{~g}$ of ammonium chloride were dissolved in solution. The $\mathrm{pH}$ of the solution was adjusted to approximately 7 to 8 using an ammonia solution. Then, $25 \mathrm{~mL}$ of linseed oil containing $0.5 \mathrm{wt} . \%$ of cobalt naphthenate drier (dual core) or $25 \mathrm{~mL}$ of linseed oil containing $0.5 \mathrm{wt} \%$ cobalt naphthenate drier with $5 \mathrm{~mL}$ of $50 \mathrm{wt} \%$ of Alcophor AC solution in xylene (multicore; AC Solutions, Fairbanks, AK, USA) was added slowly to form an emulsion and allowed to stabilize for $30 \mathrm{~min}$ under agitation. After stabilization, 6.486 g of $37 \%$ formaldehyde solution was added slowly under agitation. The temperature was raised slowly and maintained at $65^{\circ} \mathrm{C}$ under stirring at $250 \mathrm{rpm}$ for $2 \mathrm{~h}$, leading to the formation of microcapsules with PF polymer as shell and multicore materials comprising of linseed oil, drier, and corrosion inhibitor. To strengthen the shell, the PF polymer was further crosslinked by adding $5 \mathrm{wt}$.\% of $\mathrm{HCl}$ maintaining the $\mathrm{pH}$ at about 3 followed by the addition of $0.5 \mathrm{~g}$ of resorcinol. The reaction mixture was stirred at $65^{\circ} \mathrm{C}$ for about $2.5 \mathrm{~h}$, and then, the reaction mixture was cooled to ambient temperature. Microcapsules from the suspension were recovered by filtration under vacuum, rinsed with water, washed with xylene to remove suspended oil, and then dried under vacuum.

\section{Conclusions}

The linseed oil along with dried and corrosion inhibitor was successfully microencapsulated in phenol formaldehyde microcapsules.

1. Phenol formaldehyde was found to be an effective encapsulating material for linseed oil, drier, and corrosion inhibitor.

2. The microcapsule size could be effectively controlled by agitation (stirring) rate.

3. The rough or tough surface morphology of the microcapsules provides good anchorage between the coating matrix and the substrate.

4. The multicore material inside the PF microcapsules used as a healing material remains intact on coating till it is required for crack filling application (selfhealing application).
5. Corrosion inhibitor along with linseed oil prevents corrosion in scribed line region.

6. Linseed oil heals the cracks efficiently by oxidation and cures the mechanical cracks developed during stresses; furthermore, it also acts as an anticorrosive agent on the surface of the matrix.

The present investigation could be useful for further research to minimize the problems of metal corrosion through self-healing process.

\section{Competing interests}

The authors declare that they have no competing interests.

\section{Authors' contributions}

RSJ participated in paint formulation experiments for this research project, AVB participated in polymer synthesis experiments for this research project, VM participated in paint characterization, DGH guided in the polymer synthesis, PPM guided in the polymer synthesis and inference of spectroscopic analysis, and GW guided in paint formulation and characterization. All authors read and approved the final manuscript.

\section{Acknowledgments}

The authors acknowledge the support from School of Chemical Sciences, North Maharashtra University and Shalimar Paints Ltd. for jointly carrying out this research project.

\section{Author details}

${ }^{1}$ Research and Development Center, Shalimar Paints, Ltd., Nasik, Maharashtra 422403, India. ${ }^{2}$ School of Chemical Sciences, North Maharashtra University, P.B. No. 80, Jalgaon, Maharashtra 425001, India.

Received: 12 October 2012 Accepted: 26 April 2013

Published: 11 May 2013

\section{References}

1. Pascu O, Garcia-Valls R, Giamberini M (2008) Interfacial polymerization of an epoxy resin and carboxylic acid for the synthesis of microcapsules. Polym Int 57:995-1006

2. Liu X, Sheng X, Lee JK, Kessler MR (2009) Synthesis and characterization of melamine-urea-formaldehyde microcapsules containing ENB-based selfhealing agents. Macromol Mater Eng 294:389-395

3. Giraud S, Bourbigot S, Rochery M, Vroman I, Tighzert L, Delobel R (2002) Microencapsulation of phosphate: application to flame retarded coated cotton. Polym Degrad Stab 77:285-297

4. Krishnan S, Bhosale R, Singhal RS (2005) Microencapsulation of cardamom oleoresin: evaluation of blends of gum Arabic, maltodextrin and a modified starch as wall materials. Carbohydr Polym 61:95-102

5. Mcilroy DA, Blaiszik JB, Caruso MM, White SR, Moore JS, Sottos NR (2010) Microencapsulation of a reactive liquid-phase amine for self-healing epoxy composites. Macromol 43:1855-1859

6. White SR, Caruso MM, Moore JS (2008) Autonomic healing of polymers. MRS Bull 33:766-769

7. Cho SH, White RS, Braun PV (2009) Self-healing polymer coatings. Adv Mater 21:645-649

8. White SR, Sottos NR, Geubelle PH, Moore JS, Kessler MR, Sriram SR, Brown EN, Viswanathan S (2001) Autonomic healing of polymer composites. Nature (London) 409:794-797

9. Eukaszczyk J, Urba P (1997) Influence of the parameters of encapsulation process and of the structure of diisocyanates on the release of codeine from resinate encapsulated in polyurea by interfacial water promoted. Polyreaction React Funct Polym 33:233-239

10. Lee $Y H$, Kim CA, Jang WH, Choi HJ, Jhon MS (2001) Synthesis and electrorheological characteristics of microencapsulated polyaniline particles with melamine-formaldehyde resins. Poly 42:8277-8283

11. Liu XD, Ataroshi T, Furuta T, Yoshii HF, Ashima S, Okiawara M, Linko P (2001) Microencapsulation of emulsified hydrophobic flavours by spray drying. Drying Technol 19:1361-1374 
12. Park SJ, Shin YS, Lee JR (2001) Preparation and characterization of microcapsules containing lemon oil. J Colloid Interface Sci 241:502-508

13. Park BJ, Lee JY, Sung JH, Choi HJ (2006) Microcapsules containing electrophoretic suspension of $\mathrm{TiO}_{2}$ modified with poly(methyl methacrylate). Curr Appl Phys 6:632-635

14. Nelson G (2002) Application of microencapsulation in textiles. Int J Pharm 242:55-62

15. Orive G, Hernandez RM, Gasco AR, Calafiore R, Chang TMS, Vos P, Hortelano G, Lacyk DHI, Pedraz JL (2004) History, challenges and perspectives of cell microencapsulation. Trends Biotechnol 22:87-92

16. Jadhav RS, Hundiwale DG, Mahulikar PP (2011) Synthesis and characterization of phenol formaldehyde microcapsules containing linseed oil and its use in epoxy for self-healing and anticorrosive coating. J App Poly Sci 119:2911-2916

17. Suryanarayana C, Rao KC, Kumar D (2008) Preparation and characterization of microcapsules containing linseed oil and its use in self-healing coatings. Prog Org Coat 63:72-78

18. Stuart B (2004) Infrared spectroscopy: fundamentals and applications. JohnWiley \& Sons, Ltd. ISBNs: 0-470-85427-8 (HB); 0-470-85428-6 (PB)

19. Poljansek I, Krajnc M (2005) Characterization of phenol-formaldehyde prepolymer resins by in line FT-IR spectroscopy. Acta Chim Slov 52:238-244

20. Tulloch AP (1966) Solvent effects on the nuclear magnetic resonance spectra of methyl hydroxyl stearates. J Am Oil Chem Soc 43:670-674

21. Knothe $G(2006){ }^{1} H$-NMR spectroscopy of fatty acids and their derivatives hydroxy and hydroperoxy fatty acids. The AOCS Lipid Library, Urbana

22. Yang J, Keller MW, Moore JS, White SR, Sotto NR (2008) Microencapsulation of isocyanate for self healing polymers. Macromolecules 41:9650-9655

doi:10.1186/2228-5547-4-31

Cite this article as: Jadhav et al:: Synthesis of multicore phenol

formaldehyde microcapsules and their application in polyurethane paint formulation for self-healing anticorrosive coating. International Journal of Industrial Chemistry 2013 4:31.

\section{Submit your manuscript to a SpringerOpen ${ }^{\circ}$ journal and benefit from:}

- Convenient online submission

- Rigorous peer review

- Immediate publication on acceptance

- Open access: articles freely available online

- High visibility within the field

- Retaining the copyright to your article 